\title{
Hydrogen Retention in Tetraphenylborate Slurries
}

by

R. A. Peterson

Westinghouse Savannah River Company

Savannah River Site

Aiken, South Carolina 29808

This paper was prepared in connection with work done under the above contract number with the U.S. Department of Energy. By acceptance of this paper, the publisher and/or recipient acknowledges the U.S. Government's right to retain a nonexclusive, royalty-free license in and to any copyright covering this paper, along with the right to reproduce and to authorize others to reproduce all or part of the copyrighted paper. 


\section{DISCLAIMER}

This report was prepared as an account of work sponsored by an agency of the United States Government. Neither the United States Government nor any agency thereof, nor any of their employees, makes any warranty, express or implied, or assumes any legal liability or responsibility for the accuracy, completeness, or usefulness of any information, apparatus, product, or process disclosed, or represents that its use would not infringe privately owned rights. Reference herein to any specific commercial product, process, or service by trade name, trademark, manufacturer, or otherwise does not necessarily constitute or imply its endorsement, recommendation, or favoring by the United States Government or any agency thereof. The views and opinions of authors expressed herein do not necessarily state or reflect those of the United States Government or any agency thereof.

This report has been reproduced directly from the best available copy.

Available to DOE and DOE contractors from the Office of Scientific and Technical Information, P.O. Box 62, Oak Ridge, TN 37831; prices available from (615) 576-8401.

Available to the public from the National Technical Information Service, U.S. Department of Commerce, 5285 Port Royal Road, Springfield, VA 22161. 


\section{DISCLAIMER}

Portions of this document may be illegible in electronic image products. Images are produced from the best available original document. 
Amerine, D. B., 704-56H

Barnes, J. L., 704-S

Barnes, M. J., 773-A

Bragg, T. K., 241-197H

Britt, T. E., 732-B

Carter, J. T., 704-25S

Cauthen, G. L., 241-119H

Clark, W. C., 241-119H

Crawford, C. L., 773-41A

Doughty, D. E., 704-56H

Eberlein, S. J., 704-56H

Eibling, R. E., 704-T

Elder, H. H., 241-121H

Fink, S. D., 773-A

Fowler, J. R., 704-Z

Hitchler, M. J., 992W-1

Hobbs, D. T., 773-A

Holtzscheiter, E. W., 773-A

Hsu, C. W., 773-A

Hsu, R. H., 773-43A

Hyder, M. L., 773-A

ITP Library (c/o A. G. Wiest), 241-119H

Kirkland, Penny, 703-46A, Rm 203

Jacobs, R. A., 704-T

Johnson, M. D., 704-56H

Keefer, M. T., 241-153H

Landon, L. F., 704-T

Lewis, B. L., 703-H

Lex, T. J., 719-4A

Lowe, P. E., 773-42A

Marek, J. C., 704-T

McCabe, D. J., 773-43A

McCullough, J. W., 703-H

Melton, W. L., 241-154H

Menna, J. D., 730-2B

Miller, M. S., 704-72S

Montini, M. J., 704-56H

Morin, J. P., 719-4A

Nash, C. A., 676-1T

Nelson, L. M., 773-43A

Norkus, J. K., 730-2B

Papouchado, L. M., 773-A

Peterson, R. A., 676-T

Pettigrew, W. H., 704-S

Piccolo, S. F., 704-56H

Randall, C. T., 704-T

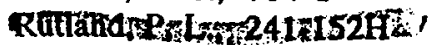

Satterfield, R. M., 719-4A

Suggs, P. C., 703-H

Swingle, R. F., 773-A

Tamosaitis, W. L., 773-A

Taylor, G. A., 241-121H

Thomas, J. K., 730-2B

Van Pelt, W. B., 679-T

Walker, D. D., 773-A

Walker, W. C., 241-82H

Wiggins, A. W., 241-84H

Wilmarth, W. R., 773-42A

Wooten, A. L., 732-B

Wright, G. T., 773-A

IWT-LWG Files, 773-A

TIM (4), 703.43A 
R. A. Peterson $R A P$

Publication Date: July 16, 1997

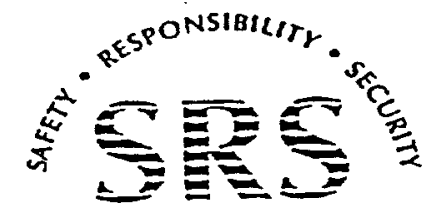


WSRC-TR-97-0206

Revision 0

Page 2 of 12

July 16, 1997

\section{SUMMARY}

Researchers measured the production and retention of gases in potassium tetraphenylborate (KTPB) slurries due to radiolysis. Analysis of these experiments produce the following conclusions:

- Concentrated (i.e., 12 wt \%) KTPB slurries retain greater than $70 \%$ of the hydrogen produced by radiolysis.

- Exposure to radiation doses to $80 \mathrm{Mrad}$ does not significantly change the hydrogen retention capacity of KTPB slurries.

- Less concentrated (ca. 1 wt \%) KTPB slurries do not retain significant quantities of hydrogen.

- Hydrogen formation rates from this study agree well with those predicted from previous laboratory work.

- Nitrous oxide forms in these slurries at rates at least a hundred-fold less than observed for hydrogen.

- Conservative calculations should employ previous, more accurately determined, nitrous oxide $G$ values.

\section{INTRODUCTION}

Since the addition of fresh material to Tank $48 \mathrm{H}$ in September of 1995 , personnel made frequent measurements of hydrogen concentration in the tank vapor space. ${ }^{1}$. These measurements show hydrogen is released from the slurry in the tank upon agitation. Previous laboratory work ${ }^{2}$ showed measurable quantities of hydrogen produced by radiolysis. Retention of hydrogen within Tank $48 \mathrm{H}$ and Tank $49 \mathrm{H}$ poses a potential safety concern. ${ }^{3}$ Retention of hydrogen results in changes to the safety basis for these tanks. High Level Waste Engineering (HLWE) requested that Savannah River Technology Center (SRTC) personnel measure the hydrogen retention capacity of tetraphenylborate slurries. ${ }^{4}$

Work performed at Pacific Northwest National Laboratory (PNNL) determined the quantity of gases retained in sludge materials. These results indicate that for yield strengths of approximately $10 \mathrm{~Pa}$, the sludges studied could retain as much as $20 \%$ of their volume as gases. ${ }^{5}$ Because the yield strength for fresh tetraphenylborate slurries ranges between 5 and $30 \mathrm{~Pa}$, depending on the tetraphenylborate concentration, these slurries could also retain large volumes of gas. The results presented in this report quantify the ability of tetraphenylborate slurries to retain hydrogen at conditions approximating the operations of the In-Tank Precipitation (ITP) facility.

\section{RESULTS}

This work involved preparation and irradiation of tetraphenylborate slurries. Prior to irradiation, researchers sealed the vial, purged the vial vapor space with nitrogen, and measured the mass of the slurry in the vial. Following each test, researchers sampled, purged, and agitated the systems. Personnel considered the vapor space adequately purged if $<10 \%$ of the hydrogen remained in the vapor. Researchers then analyzed the vapor space for retained gases, primarily hydrogen and nitrous oxide. Personnel repeated this process to ensure that $>90 \%$ of the hydrogen released from the slurry. Figure 1 provides a schematic diagram of the experimental protocol. A Technical Notebook contains the results of these measurements as a permanent record. ${ }^{6}$ Appendix A provides a detailed description of the experimental protocol and the sample results. 
Figure 1. Experimental Flow Diagram.

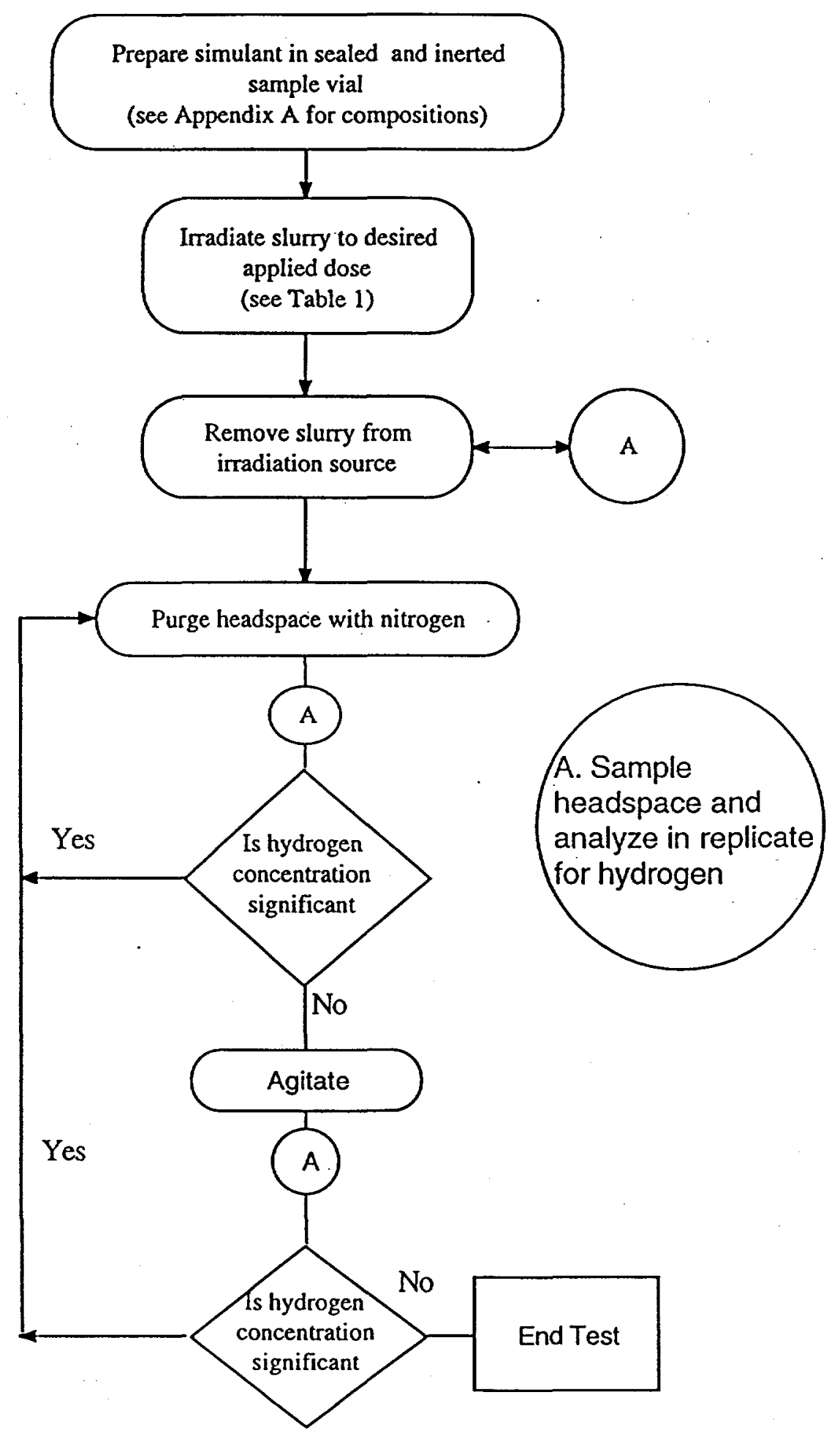




\section{Test Conditions}

Researchers investigated the impact of several variables on the amount of hydrogen retained. The variables include the rate of hydrogen generation (as controlled by the dose rate), the total quantity of hydrogen generated (as controlled by the total dose), the salt concentration of the slurry, the weight percent solid KTPB in the slurry and the previous irradiation dose received by the slurry.' Personnel controlled the rate of hydrogen generation by using two different irradiation rates and by employing two different salt concentrations. The irradiation dose received by the sample directly controlled the quantity of hydrogen generated. Table 1 lists the variable levels for the 10 tests in this study. Note that all but one of these use the maximum solid concentration anticipated during plant operations. Low nitrate and nitrite concentrations will increase hydrogen generation rates by as much as an order of magnitude. ${ }^{3}$ Therefore, hydrogen production in washed slurries will prove more problematic than in unwashed slurries. Hence, the majority of the tests used lower nitrate and nitrite concentrations.

The dose rate used exceeds those anticipated during plant operations. However, the lower limit of the range of dose rates used $(0.0258 \mathrm{Mrad} / \mathrm{hr})$ approaches the maximum anticipated dose rate of $0.017 \mathrm{Mrad} / \mathrm{hr}$. Note that at the low dose rates, diffusion played a significant role in the release of hydrogen from the slurry (see Appendix B). Also, in a large volume of slurry containing high solids concentrations, such as at the end of the concentration cycle in Tank $48 \mathrm{H}$ or during storage in Tank $49 \mathrm{H}$, diffusion will penetrate less than $30 \mathrm{~cm}$ from the top surface of the slurry. ${ }^{8}$ Thus, the bulk of the slurry will not participate in diffusion and the retentive behavior of the slurry will better agree with that observed at higher dose rates. Therefore, to decrease the impact of diffusion on the measured retention capability of the slurries, the bulk of these tests used a higher dose rate (1.3 $\mathrm{Mrad} / \mathrm{hr}$ ). While slurry stored in Tank $49 \mathrm{H}$ should experience a cumulative dose exceeding 200 Mrad, ${ }^{9}$ previous work showed the majority of the changes in rheological properties associated with radiation exposure of KTPB slurry occur during the first $30 \mathrm{Mrad}$ of dose. Also, essentially no changes in rheological properties occur as the dose increases above $50 \mathrm{Mrad}^{9}$. Work at PNNL shows the retentive capability of slurries depends upon the rheological properties of a slurry. ${ }^{5}$. To study the impact of rheological changes on hydrogen retention, researchers exposed slurries to an irradiation dose prior to measuring the hydrogen retention of the slurry. Applied doses included $24 \mathrm{Mrad}$ and 61 Mrad for selected slurries followed by an additional applied dose as indicated in Table 1.

Table 1. Matrix of hydrogen retention tests

$\begin{array}{cccccc}\text { Test \# } & \begin{array}{c}\text { Salt } \\ \text { Concentration } \\ (\mathrm{M})\end{array} & \begin{array}{c}\text { Dose Rate } \\ (\mathrm{Mrad} / \mathrm{h})\end{array} & \begin{array}{c}\text { wt \% } \\ \text { tetraphenylborate } \\ \text { solid }\end{array} & \begin{array}{c}\text { Applied dose } \\ \text { (Mrad) }\end{array} & \begin{array}{c}\text { Previous } \\ \text { dose (Mrad) }\end{array} \\ 1 & 0.5 & 1.39 & 12 & 7.76 & 61 \\ 2 & 0.5 & 1.32 & 12 & 1.55 & 0 \\ 3 & 0.5 & 1.32 & 12 & 1.55 & 61 \\ 4 & 0.5 & 1.39 & 12 & 7.76 & 0 \\ 5 & 0.5 & 1.39 & 12 & 4.09 & 24 \\ 6 & 0.5 & 1.39 & 12 & 4.09 & 24 \\ 7 & 0.5 & 0.0258 & 12 & 4.80 & 24 \\ 8 & 0.5 & 0.0258 & 12 & 4.80 & 24 \\ 9 & 5.0 & 1.39 & 12 & 81.8 & 0 \\ 10 & 5.0 & 1.39 & 1 & 81.8 & 0\end{array}$




\section{Hydrogen and Nitrous Oxide Generation}

Researchers calculated the quantity of hydrogen produced for each test listed in Table 1. From these calculations, one may determine a hydrogen $G$ value for each test (see Appendix B). (The $G$ value defines the number of molecules produced per $100 \mathrm{eV}$ of energy absorbed.) Note that personnel repeated Test \#3 due to experimental difficulties discussed later in this document. In addition, Table 2 lists the nitrous oxide $G$ values calculated for a limited number of the tests. Figure 2 plots the hydrogen $G$ values. with previously measured values. ${ }^{2}$ Table 2 contains the results of these calculations.

\section{Table 2. Experimentally Determined Hydrogen and Nitrous Oxide G values \\ Test \#

1
2
3
$3 \mathrm{~A}$
4
5
6
7
8
9
10 Total \\ $\mathrm{H}_{2} \mathrm{G}$ Value \\ (molecules/100 eV) \\ 0.229 \\ 0.249 \\ 0.262 \\ 0.255 \\ 0.249 \\ 0.215 \\ 0.240 \\ 0.195 \\ 0.127 \\ 0.064 \\ $0.017 \quad .00001$ \\ Retained \\ $\mathrm{N}_{2} \mathrm{O} G$ Value \\ (molecules $/ 100 \mathrm{eV}$ ) \\ 0.00057 \\ NM \\ NM \\ 0.00062 \\ NM \\ NM \\ NM \\ ND \\ ND \\ .00008 \\ .00001 \\ NM: Not measured ND: Not detected (limit of 0.00001 molecules $/ 100 \mathrm{eV}$ )}

Figure 2. Measured Hydrogen $G$ Values
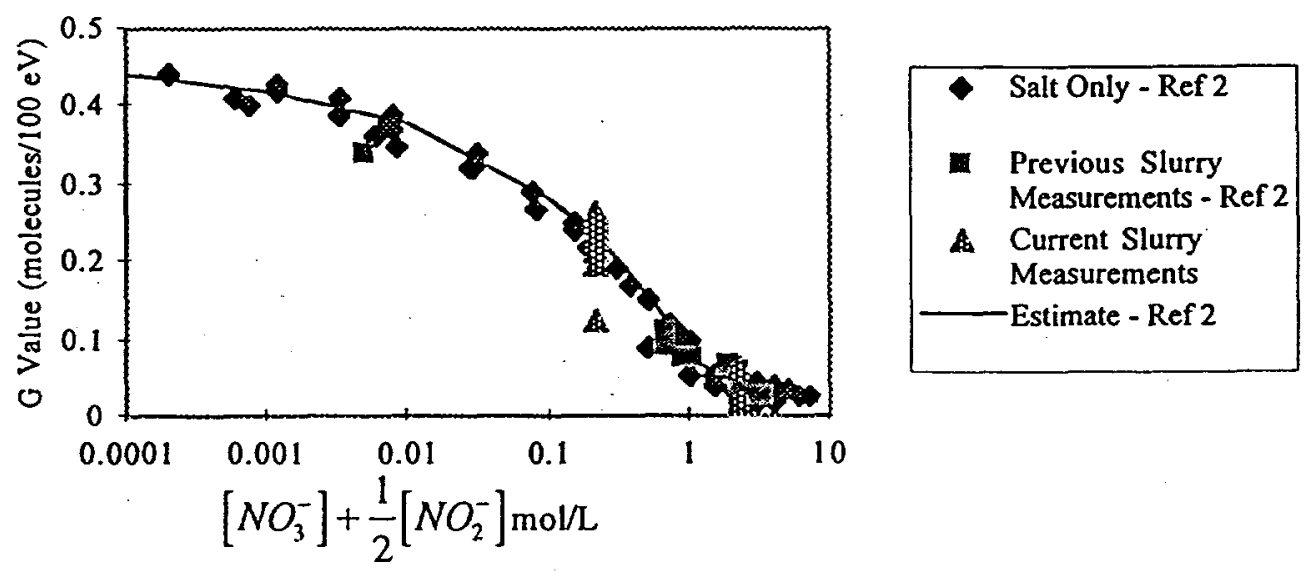

Inspection of Figure 2 indicates that, for Tests 1 through 6 , the hydrogen $G$ value agrees well with those determined previously. The hydrogen $G$ values determined for Test 8 appears significantly lower. This difference likely reflects loss of hydrogen from the test vials during the extended irradiation period. Tests 7 and 8 required approximately 1 week to achieve the desired irradiation dose. (In contrast, Tests 1 through 6 completed within 1 shift.) During this extended irradiation 
period, significant quantities of hydrogen likely released from the sample vials, resulting in the total measured hydrogen being lower than anticipated, based on the irradiation dose. Thus the calculated $G$ values from experimental measurements are also lower. Similarly, the lower than anticipated $G$ value from Test 10 also likely results from release of hydrogen. This test showed limited hydrogen retention due to the low solid content in the sample. In addition, the high dose employed in this test led to significant degradation of the sample vial septum. These two experimental conditions likely led to a significant release of hydrogen from this vial prior to sampling and thus account for the lower than anticipated $G$ value. Note that the average $G$ value for Tests 1 through 6 measures 0.24 molecules $/ 100 \mathrm{eV}$ with a standard deviation of 0.02 . This result agrees well with the previously measured hydrogen $\mathrm{G}$ values.

Further inspection of Table 2 indicates only limited quantities of nitrous oxide formed in these tests. The nitrous oxide concentrations in these slurries rarely exceeded the detection limit. These measurements significantly lower than previously measured nitrous oxide $G$ values. ${ }^{10}$ Hence, use of previously measured $G$ values in estimating nitrous oxide generation rates gives conservative values by at least an order of magnitude. Also note the measured nitrous oxide $G$ values often fall two orders of magnitude lower than the hydrogen $G$ values.

\section{Measured Hydrogen Retention}

Researchers also calculated the quantity of hydrogen retained in the slurry. Figure 3 plots the percentage of hydrogen produced that remained in the slurry as a function of total dose received. Inspection of Figure 3 indicates between $70 \%$ and $85 \%$ hydrogen retention measured for 6 of the 7 tests in sequence 1 through 6 . Note that these measured retention capacities represent a lower limit; actual retention in a High Level Waste tank may prove higher due to the limited impact of diffusion upon those tanks. ${ }^{8}$ Less than $40 \%$ retention occurred in Test 3 . However, researchers noted that for Test 3, the sample vial appeared agitated prior to sampling. Repeating Test 3 resulted in $73 \%$ hydrogen retention, consistent with results from the other five test conditions.

Further inspection of Figure 3 indicates that both Tests 7 and 8 showed significantly lower hydrogen retention (i.e., $\leq 20 \%$ ). As noted previously, this lower hydrogen retention likely results from diffusion of hydrogen from the slurry during the extended irradiation time period. Therefore, these lower hydrogen retention values do not represent anticipated Tank $49 \mathrm{H}$ hydrogen retention values. Tests 7 and 8 also exhibited lower calculated $G$ values than anticipated from previous studies. However, since these tests showed significant loss of hydrogen to the vapor space due to the longer test time and the higher vapor space hydrogen concentration increasing the loss of hydrogen through the seals of the vials, these $G$ values likely do not reflect the actual system $G$ values.

Figure 3 also presents hydrogen retention for Tests 9 and 10. Test 10 gave the lowest measured hydrogen retention. The slurry employed in Test 10 contained only $1 \mathrm{wt} \% \mathrm{KTPB}$ solids. At this low solid concentration, the yield strength of the slurry diminishes to a negligible value, and thus the capacity of the slurry to retain hydrogen as bubbles greatly diminishes. (Note that in no case produced visible hydrogen bubbles; however, slight level increases resulted in a number of tests.) Thus, researchers anticipated this slurry would exhibit minimal hydrogen retention. As in the case of Tests 7 and 8 , this minimal retention likely contributed to the significantly lower hydrogen $G$ value found. 
Figure 3. Hydrogen Retention

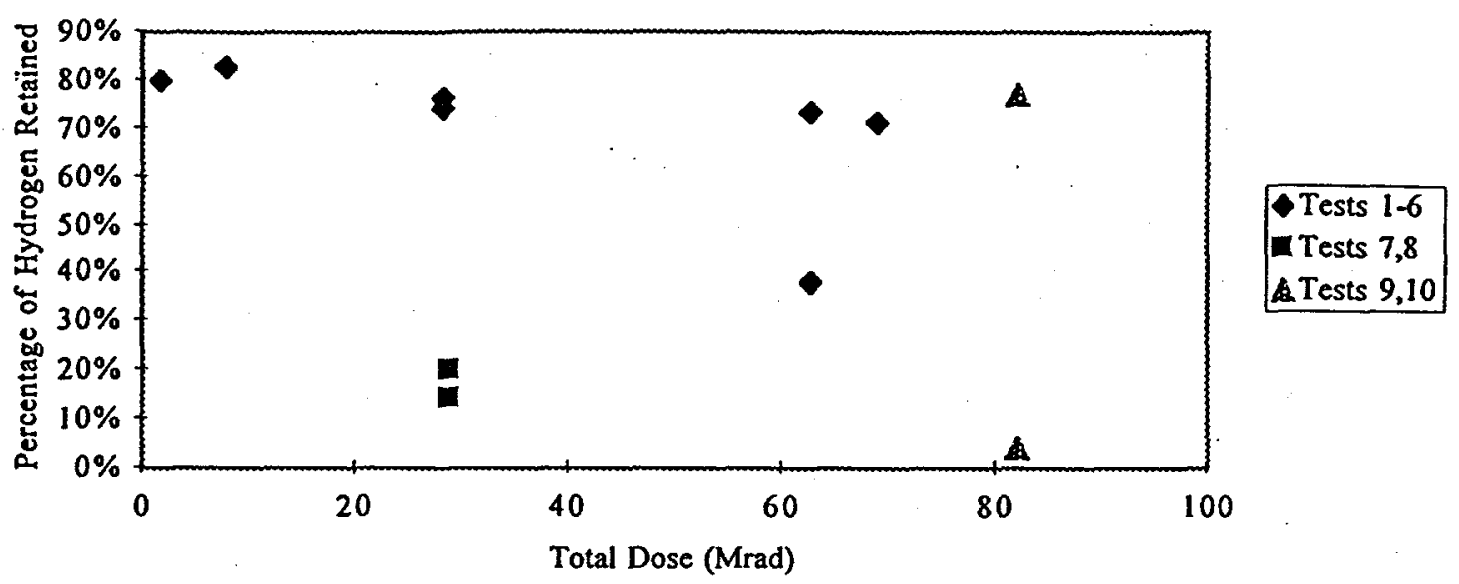

\section{CONCLUSIONS}

Researchers measured hydrogen and nitrous oxide generation in a number of tetraphenylborate slurries. Calculated hydrogen $\mathrm{G}$ values agree extremely well with previous hydrogen measurements. Measured nitrous oxide generation rates proved significantly lower than anticipated. Both the anticipated and measured nitrous oxide $G$ values remain significantly (i.e., more than an order of magnitude) lower than the measured hydrogen $G$ values. The $12 \mathrm{wt} \%$ slurries retained in excess of $70 \%$ of the hydrogen. Decreasing the slurry concentration until the slurry shows negligible yield strength effectively removes most of the slurry retention capacity for hydrogen. However, irradiation of slurry to $80 \mathrm{Mrad}$ total dose did not reduce yield strength sufficiently to significantly reduce the retentive capacity of the slurries. Note that $1 \mathrm{wt} \%$ precipitate does not exhibit a yield strength while $12 \mathrm{wt} \%$ slurries exposed to high irradiation doses still retain at least a minimal yield strength of 0.1 to $0.6 \mathrm{~Pa}^{9}$. Thus, the observation of continued retention for slurries exposed to high irradiation doses agrees with anticipated results based on measured yield strengths. Researchers also found that for small-scale testing (i.e., slurry depth of $2-4$ inches), diffusion can significantly deplete samples of hydrogen. However, significant depletion by diffusion is not expected in Tanks $48 \mathrm{H}$ or $49 \mathrm{H}$ due to a much thicker layer of solids that would retard diffusion of gas bubbles that form. 


\section{REFERENCES}

' R. A. Peterson, R. F. Swingle, "Hydrogen Retention and Release Summary From Tank 48H from September 1995 to October 1996 (U), WSRC-TR-97-0043, February 10, 1997.

${ }^{2}$ C.L. Crawford and D.D. Walker, "Hydrogen Generation by Radiolysis of Tetraphenylborate Solutions and Slurries (U)", WSRC-TR-96-0109, June 19, 1996.

${ }^{3}$ J.K. Thomas and T.E. Britt, "Potential Inadequacy: Gas Trapping in ITP Waste Tank (U)", EPD-DBA-94-0134, December 15, 1994.

4 J.E. Marra, Technical Task Request, HLE-TTR-97039, February 3, 1997.

${ }^{5}$ P.A. Gauglitz, S.D. Rassat, P.R. Bredt, J.H. Konynenbelt, S.M. Tingey, D.P. Mendoza, "Mechanisms of Gas Bubble Retention and Release: Results for Hanford Waste Tanks 241-S-102 and 241-SY-103 and Single-Shell Tank Simulants", PNNL-1 1298, September 1996.

${ }^{6}$ R.A. Peterson, Laboratory Notebook, WSRC-NB-94-271, June 13, 1997.

${ }^{7}$ R.A. Peterson, "Task Technical Plan for Hydrogen Retention (U)", WSRC-RP-97-255, April 28, 1997.

"R.A. Peterson, "Anticipated Fate of Hydrogen in Radioactive Wastes (U)", WSRC-TR-97-xxx, June 30, 1997.

'D.D. Walker and J.P. Doherty, "The Effects of Gamma Irradiation on the Rheology of KTPB Slurries", DPST85-926, November 5, 1985.

${ }^{10}$ D.D. Walker, D.T. Hobbs, J.B. Tiffany, N.E. Bibler, and D. Meisel, "Nitrous Oxide Production From Radiolysis of Simulated High-Level Nuclear Waste Solutions", Waste Management 92, March 1, 1992.

S. D. Fink, Manager, WPTS-LWP
C. Crawford, Desigh Check


Appendix A. Experimental Protocol and Results.

Sample Measurements:

All vapor space sample measurements used a Varian 3400 gas chromatograph employing a molecular sieve column and thermal conductivity detector (TCD).

Prior to and following each set of sample measurements, personnel analyzed samples from standard gases provided by Scott Specialty Gases. These standards ranged from 0.9991 to 10 volume \% hydrogen. In addition, the work used a 20 vol \% nitrous oxide standard.

Sample Preparation:

Researchers perpared samples to the specification listed in Table A.1 and added each 80 gram sample to a $\sim 160 \mathrm{~mL}$ sample vial of known weight and volume. Table A.2 provides these masses. These samples were then sealed with crimp-top caps and Teflon insert. These samples were then purged with nitrogen for 5 minutes prior to irradiation. Samples requiring pre irradiation were irradiated in an open vessel and then stirred overnight to remove any entrained hydrogen prior to receiving the applied irradiation dose. This overnight agitation was significantly more vigorous than employed during sampling measurement. Since the agitation employed during sampling measurement was sufficient to release nearly all of the retained hydrogen, the assumption was made that these samples were effectively depleted of hydrogen prior to receiving the applied irradiation dose.

Table A.1: Slurry Compositions

\begin{tabular}{|c|c|c|c|}
\hline Component & $\begin{array}{c}\text { Tests } 1-8 \\
\text { Concentration in } \\
0.5 \mathrm{M} \mathrm{Na}^{+} \text {Salt } \\
\text { Solution (M) } \\
12 \text { wt \% KTPB } \\
\end{array}$ & $\begin{array}{c}\text { Test } 9 \\
\text { Concentration in } \\
5 \mathrm{M} \mathrm{Na}^{+} \text {Salt } \\
\text { Solution (M) } \\
12 \text { wt \% KTPB }\end{array}$ & $\begin{array}{c}\text { Test } 10 \\
\text { Concentration } \\
\text { in } 5 \mathrm{M} \mathrm{Na}^{+} \text {Salt } \\
\text { Solution (M) } \\
1 \text { wt } \% \text { KTPB }\end{array}$ \\
\hline $\mathrm{NaOH}$ & 0.0 & 2.34 & 2.72 \\
\hline $\mathrm{NaNO}_{3}$ & .05 & 1.04 & 1.04 \\
\hline $\mathrm{NaNO}_{2}$ & .06 & 0.63 & 0.63 \\
\hline $\mathrm{Al}\left(\mathrm{NO}_{3}\right)_{3} \cdot 9 \mathrm{H}_{2} \mathrm{O}$ & 0.03 & 0.33 & 0.33 \\
\hline $\mathrm{Na}_{2} \mathrm{SO}_{4}$ & 0.014 & 0.14 & 0.14 \\
\hline $\mathrm{Na}_{2} \mathrm{CO}_{3}$ & 0.015 & 0.15 & 0.15 \\
\hline $\mathrm{NaTPB}$ & 0.33 & 0.41 & 0.028 \\
\hline $\mathrm{KNO}_{3}$ & 0.05 & 0.0 & 0.0 \\
\hline $\mathrm{KOH}$ & 0.28 & 0.41 & 0.04 \\
\hline $\mathrm{Na}^{+}$ & 0.5 & 5.0 & 5.0 \\
\hline
\end{tabular}


Vapor space measurements:

Each vapor space sample measurement provided an integrated peak area. These peak areas were converted to concentrations based on the peak areas measured for the standard gases. Each sample was performed in duplicate. Table A.2 gives the averages of the duplicate calculated concentrations. The shaded area in Table A.2 contain calculated values derives as follows.

The solution mass represents the mass of the salt solution

$$
\text { Solution mass }=(1-\text { fraction solids })^{*} \text { slurry mass }
$$

The vapor volume denotes the volume of the headspace in the sample vial

$$
\text { Vapor volume }=\text { vial volume }- \text { slurry volume }
$$

The retained volume percens includes the summation of the vapor space volume measurements following each of the agitation steps.

$$
\text { Retained vol } \%=1 \text { st Agitate }+2 \text { nd Agitate }+3 \text { rd Agitate }+4 \text { th Agitate }
$$

The Retained \% represents the percentage of hydrogen found retained within the slurry.

$$
\text { Retained \% = Retained vol \%/ (Pre Agitate + Retained vol \%) }
$$

The product of the volume $\%$ found and the headspace volume gives the volume of hydrogen formed

$$
\text { Formed }(\mathrm{mL})=(\text { Pre Agitate }+ \text { Retained vol \%)*Vapor Volume }
$$

The calculations assumed standard temperature $\left(25^{\circ} \mathrm{C}\right)$ and pressure $(1 \mathrm{~atm})$ and the molar volume of hydrogen as $22400 \mathrm{~mL}$. Likewise, 1 mole of hydrogen contained $6.022 \times 10^{23}$ molecules. In addition, $1 \mathrm{Rad}$ equals $6.24 \times 10^{19} \mathrm{eV} / \mathrm{g}$. Only dose received by the salt solution (and not the KTPB solids) was assumed to produce hydrogen. Therefore, the total dose was assumed to be only that applied to the salt solution.

Total Dose $(\mathrm{eV})=$ Dose $(\mathrm{eV} / \mathrm{g}) *$ Solution Mass $(\mathrm{g})$

Finally, the $G$ value comes directly from the number of molecules of hydrogen formed and the dose applied.

$$
\mathrm{G} \text { value }=100 * \text { Formed }(\text { molecules }) / \text { Dose }(\mathrm{eV})
$$


Page 11 of 12

July 16, 1997

Table A.2. Experimental Results for Hydrogen

\begin{tabular}{|c|c|c|c|c|c|c|c|c|}
\hline Test & $\begin{array}{c}\begin{array}{c}\text { Vial Volume } \\
(\mathrm{mL})\end{array} \\
\end{array}$ & $\begin{array}{l}\text { Slunty Mass } \\
\text { (g) }\end{array}$ & Solutong & $\begin{array}{c}\text { Pre Agitate } \\
\text { (vol \%) }\end{array}$ & $\begin{array}{l}\text { Ist Agitate } \\
(\text { vol \%) }\end{array}$ & $\begin{array}{l}\text { 2nd Agitate } \\
\text { (vol \%) }\end{array}$ & $\begin{array}{l}\text { 3rd Agitate } \\
\text { (vol \%) }\end{array}$ & $\begin{array}{l}\text { 4th Agitate } \\
\text { (vol \%) }\end{array}$ \\
\hline 1 & 159.02 & 79.99 & \% & 1.035 & 2.466 & 0.083 & 0.000 & 0.000 \\
\hline 2 & 160.09 & 79.96 & 2066 & 0.155 & 0.300 & 0.137 & 0.115 & 0.063 \\
\hline 3 & 159.78 & 79.99 & 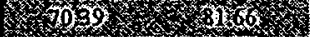 & 0.505 & 0.285 & 0.023 & 0.000 & 0.000 \\
\hline $3 \mathbf{A}$ & 160.92 & 80.01 & 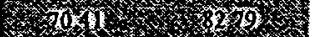 & 0.210 & 0.533 & 0.039 & 0.000 & 0.000 \\
\hline 4 & 159.85 & 80.02 & 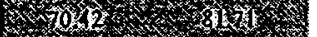 & 0.665 & 2.504 & 0.509 & 0.155 & 0.037 \\
\hline 5 & 160.58 & 80.03 & $70 \% 3$ & 0.413. & 0.786 & 0.458 & 0.048 & 0.041 \\
\hline 6 & 160.25 & 79.98 & $2038 \times$ & 0.500 & 1.255 & 0.143 & 0.017 & 0.037 \\
\hline $\begin{array}{l}7 \\
8\end{array}$ & $\begin{array}{l}160.29 \\
160.30\end{array}$ & $\begin{array}{l}80.01 \\
80.04\end{array}$ & 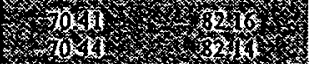 & $\begin{array}{l}1.653 \\
1.009\end{array}$ & $\begin{array}{l}0.274 \\
0.119\end{array}$ & $\begin{array}{l}0.010 \\
0.134\end{array}$ & $\begin{array}{l}0.000 \\
0.000\end{array}$ & $\begin{array}{l}0.000 \\
0.000\end{array}$ \\
\hline 9 & 160.00 & 80.02 & 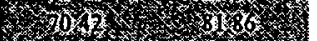 & 2.676 & 6.077 & 0.853 & 0.550 & 0.222 \\
\hline 10 & 160.26 & 80.01 & 6221 & 2.909 & 0.096 & 0.028 & 0.000 & 0.000 \\
\hline est & solos & (tol & 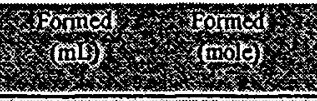 & tortoded & $\begin{array}{l}\text { Dose } \\
\text { (Mrad) }\end{array}$ & oros & (x) & 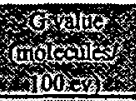 \\
\hline 1 & $2 \times 2510$ & DIV & 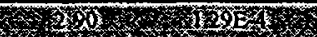 & (60) 19 & 7.76 & $884 \mathrm{~B}_{20}$ & 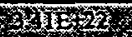 & 029, \\
\hline 2. & 1,066 & $200 \%$ & 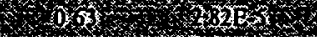 & 100010 & 1.55 & DD 60 & 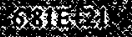 & $028 \%$ \\
\hline 3 & \%opos & $428 \%$ & 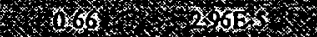 & 1786.19 & 1.55 & $0,6 \mathrm{~s}$ & $6,3 \mathrm{E}_{3}, \mathrm{~s}$ & $020 \%$ \\
\hline $3 A$ & 0,81 & os $1 \%$ & 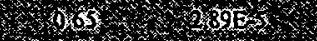 & ats 3 & 1.55 & $28 \mathrm{dg} \times 10$ & o $8>1$ & 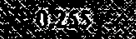 \\
\hline 4 & $\times 305$ & $8,8 \%$ & 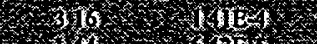 & $600 \mathrm{~g} g$ & 7.76 & Hon E & WE & 020 \\
\hline 5 & xas & 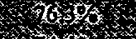 & 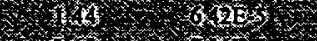 & $80_{10}$ & 4.09 & 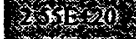 & $3 / 0 \mathrm{O}, 2 \%$ & $00 x+3$ \\
\hline 6 & 40 & 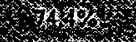 & $8,160 \%$ & $36 \mathrm{ESOM}$ & 4.09 & $3,36+20$ & 1so & 0400 \\
\hline 7 & S $0128 \mathrm{~s}$ & 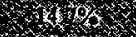 & 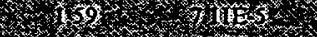 & $28 \mathrm{E} 2 \mathrm{k}$ & 5.00 & 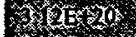 & $<100$ & 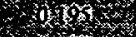 \\
\hline 8 & $x>58$ & z $200 \%$ & 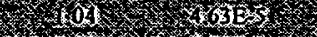 & 22819 & 5.00 & 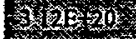 & $20 \mathrm{~b}$ & $0,5 \%$ \\
\hline 9 & s 902 & $=7,28$ & * $850 \%$, & $28 \mathrm{~B}_{2} 0$ & 81.8 & S $10 \mathrm{E} 2 \mathrm{z}$ & $\triangle 10 \mathrm{E} 23$ & 4664 \\
\hline 10 & - $15 \% 4$ & 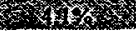 & 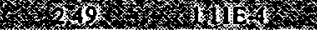 & $420 \mathrm{E}=\mathrm{g}$ & 81.8 & WOE 2 & 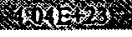 & Wat \\
\hline
\end{tabular}


Appendix B. Diffusion Estimates.

Diffusion in these systems is defined by the Continuity Equation.

$\frac{d C_{H}}{d t}=D_{H B} \frac{d^{2} C_{H}}{d x^{2}}+G e n_{H}$

where $C_{H}$ is the concentration of hydrogen at position $(x, t), D_{H B}$ is the diffusivity of hydrogen in salt solution and $\mathrm{Gen}_{\mathrm{H}}$ is the hydrogen generation rate. This equation can be made dimensionless by normalization with the following parameters

$$
\begin{aligned}
& \bar{C}=\frac{C_{H}}{C_{G}} \\
& \bar{t}=\frac{t}{\tau} \\
& \bar{x}=\frac{x}{l}
\end{aligned}
$$

where $C_{G}$ is the solubility of hydrogen, $\tau$ is the characteristic time of the system and 1 is the characteristic length of the system. This normalization produces:

$$
\frac{d \bar{C}}{d \bar{t}}=\frac{d^{2} \bar{C}}{d \bar{x}^{2}}+1
$$

The characteristic time and length can be defined as:

$$
\begin{aligned}
& \tau=3.78 \times 10^{6} * \frac{C_{G}}{G * \hat{h} v} \\
& l=\left(D_{H B} \tau\right)^{1 / 2}
\end{aligned}
$$

where $C_{G}$ is the solubility of hydrogen in $\mathrm{mg} / \mathrm{L}, \mathrm{G}$ is the $\mathrm{G}$ value and $\mathrm{hv}$ is the radiolytic energy in $\mathrm{Ci} / \mathrm{gal}$. For a sample with a solubility of $1.5 \mathrm{mg} / \mathrm{L}$, a $\mathrm{G}$ value of 0.243 and a radiolytic energy of 54 $\mathrm{Ci} / \mathrm{gal}(\sim 0.025 \mathrm{Mrad} / \mathrm{hr}$ for a slurry with a density of $\sim 1 \mathrm{~g} / \mathrm{mL})$, and a diffusivity of $4.8 \times 10^{-5} \mathrm{~cm}^{2} / \mathrm{s}, \tau$ is 5.0 days and $I$ is $4.5 \mathrm{~cm}$. Solution of Equation C.5 indicates that $1.5 \times$ the characteristic length is significantly depleted by diffusion. ${ }^{8}$. For the higher dose rate of $1.32 \mathrm{Mrad} / \mathrm{hr}(\sim 2870 \mathrm{Ci} / \mathrm{gal})$, the characteristic length decreases to $0.6 \mathrm{~cm}$. 